\title{
REAÇÃO DA TIAZOLIDINADIONA COM P-ANISALDEÍDO EM BATELADA: INFLUENCIA DO CATALISADOR NO RENDIMENTO DO PRODUTO
}

\author{
C. O. LIMA', F. M. CARDOSO ${ }^{2}$, R. O. VIEIRA ${ }^{3}$, M. S. A. PALMA ${ }^{3}$ \\ ${ }^{1}$ Universidade de São Paulo, Departamento de Engenharia Química \\ ${ }^{2}$ Universidade de São Paulo, Instituto de Química \\ 3 Universidade de São Paulo, Departamento de Tecnologia Bioquímico-Farmacêutica \\ E-mail para contato: msapalma@usp.br
}

\begin{abstract}
RESUMO - Este trabalho visa a determinação de catalisadores alternativos à piperidina, cuja comercialização foi proibida, na síntese do derivado (Z)-5(4-metoxibenzilideno)tiazolidina-2,4-diona. Tomando a piperidina como referência, foram testados a morfolina, feniletilamina, propargilamina, diaminoetano e piperazina em ensaios com duração de $8 \mathrm{~h}$ em batelada em diferentes concentrações, de modo a determinar a concentração ótima para cada um dos catalisadores. Deste modo, será possível identificar o catalisador mais eficiente para a síntese em microrreatores, processo que apresenta diversas vantagens em relação ao processo em batelada, como por exemplo, maiores segurança e rendimento. A piperidina e o diaminoetano foram os melhores catalisadores em termos de velocidade inicial da reação e rendimento máximo de produto em menor tempo de reação.
\end{abstract}

\section{INTRODUÇÃO}

A 2,4-tiazolidinadiona (TZD) é um composto orgânico sintético bastante relevante para a indústria químico farmacêutica. Esta molécula foi sintetizada pela primeira vez no século XIX por Libermann et al. (1881) e é precursora de diversos fármacos importantes para o tratamento de doenças como a diabetes mellitus tipo II. Fármacos como a pioglitazona, derivado da TZD, possuem atividade biológica comprovada e já são comercializados.

Devido às suas diferentes propriedades farmacológicas como a atividade anticancerígena, anti-convulsionante, anti-hipoglicêmica, antifúngica, anti-inflamatória (Mishra et al., 2015; Mohanty et al., 2015) é de extrema importância o aprimoramento de técnicas de síntese e de modificações na molécula de TZD. A estrutura molecular da TZD está mostrada na Figura 1. 
Figura 1 - Estrutura molecular da 2,4-tiazolidinadiona (TZD).

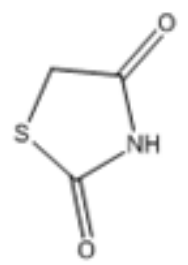

A rota de síntese de derivados da TZD mais empregada é a Condensação de Knoevenagel (Figura 2), que consiste em duas etapas. Na primeira etapa há uma adição nucleofílica à carbonila, utilizando-se uma base para a ionização do grupo metileno. Já na segunda ocorre uma desidratação e uma dupla ligação entre carbonos é formada (Cunha e Santana, 2012).

Figura 2 - Mecanismo geral da condensação de Knoevenagel

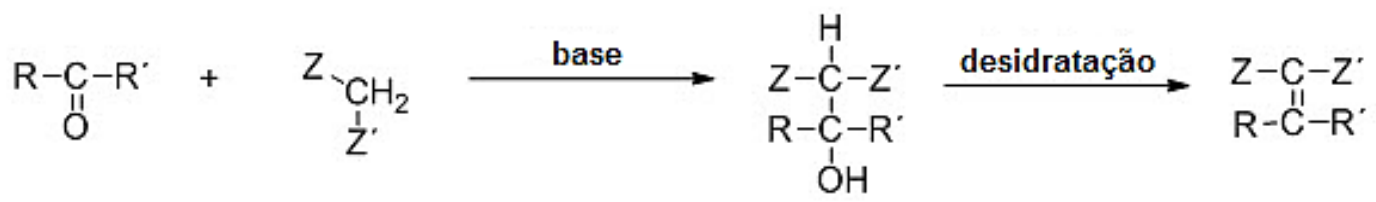

Esta reação, em geral, é realizada industrialmente no processo batelada, mas a síntese em microreatores, dispositivos constituídos de microcanais de 10 a $100 \mu \mathrm{m}$ também é possível. Este processo alternativo à síntese em batelada mostra-se vantajoso por diversos motivos. Sendo eles, por exemplo, o escoamento laminar e volume o reduzido do reator que promove altíssima relação superfície/volume, o que facilita a troca de calor no mesmo (Xu et al.,2015) e diminui o tempo de difusão dos compostos em solução, fato que reduz os tempos de reação e aumenta as taxas de conversão dos reagentes e rendimento do produto (Watts e Wiles, 2012).

Desse modo, são gerados menos resíduos, reduzindo o impacto ambiental do processo além de promover um menor custo de produção, tendo em vista a compactação das unidades industriais e o menor tempo de produção. Considerando o potencial dos microrreatores na indústria químico-farmacêutica, é necessária a prospecção por novos catalisadores que maximizem o rendimento.

Estes catalisadores devem, portanto, apresentar elevada velocidade inicial da reação visto que os tempos de residência em microrreatores são pequenos. A piperidina, catalisador comumente utilizado na síntese de derivados da TZD, teve sua 
comercialização recentemente proibida, fato que torna necessária a busca por catalisadores alternativos.

Deste modo, este estudo visa à identificação de catalisadores alternativos à piperidina que maximizem a conversão dos reagentes e rendimento do produto em microrreatores, além da determinação das concentrações ótimas para cada um dos catalisadores no meio reacional proposto buscando uma melhoria de processo.

\section{MATERIAIS E PROCEDIMENTO EXPERIMENTAL}

\subsection{MATERIAIS}

Nas reações de síntese foram utilizados: TZD e p-anisaldeído (reagentes); piperidina, morfolina, feniletilamina, propargilamina, diaminoetano e piperazina (catalisadores); etanol 99,8\% (solvente), além de uma solução Acetonitrila/ $\mathrm{H}_{2} \mathrm{O}$ 50/50\% para diluição das amostras em vials utilizados para análise em HPLC-UV. Para a cristalização e recristalização do produto foi utilizado ácido acético glacial e etanol $99,5 \%$.

\subsection{PROCEDIMENTO EXPERIMENTAL}

Em um balão de fundo redondo de $150 \mathrm{~mL}$ de três bocas foi fixado uma manta aquecedora e conectado a um condensador Allhin pela boca do meio. Em uma das bocas laterais foi conectado um termômetro e na outra eram adicionados os reagentes e, posteriormente, retiradas amostras ao longo da reação. $\mathrm{O}$ meio reacional consistia de $60 \mathrm{~mL}$ de solvente e $468 \mathrm{mg}$ de 2,4-tiazolidinadiona (TZD) (4 mmol). Aqueceu-se até temperatura de ebulição do solvente e em seguida foi adicionado $488 \mu \mathrm{L}$ (546 mg, 4 mmol) de p-anisaldeído e quantidades variadas de catalisador. Inicialmente para cada um dos catalisadores foram feitos ensaios com 2,4, 3,2 (Mishra et al, 2015) e 4,0 mmol. A partir dos resultados obtidos foram realizados outros ensaios de modo a determinar a quantidade ótima de catalisador.

O meio reacional foi mantido em refluxo por $8 \mathrm{~h}$ retirando-se amostras nos tempos 0 (após adição do catalisador), 4, 20, 80, 180, 330 e 480 min para análise em HPLC-UV. Após esse tempo o meio reacional foi deixado em descanso até se aproximar da temperatura ambiente e, então acidificado com $5 \mathrm{~mL}$ de ácido acético glacial e diluído com $60 \mathrm{~mL}$ de água destilada gelada. A mistura era então mantida por $24 \mathrm{~h}$ a $-20^{\circ} \mathrm{C}$ e então seguia as etapas de cristalização e recristalização através das quais era determinado o rendimento mássico.

\section{RESULTADOS E DISCUSSÕES}

Até o momento foram realizados ensaios preliminares com a piperidina, morfolina, feniletilamina e diamnioteano em batelada em ensaios de $8 \mathrm{~h}$.

Na Figura 3 são apresentados os resultados preliminares obtidos para a piperidina, morfolina, feniletilamina e diaminoetano. 


\section{Congresso Brasileiro de Engenharia Química em Iniciação Científica UFSCar - São Carlos - SP

Figura 3 - Gráficos de rendimento de produto para 2,4, 3,2 e 4,0 mmol dos catalisadores piperidina (A), morfolina (B), feniletilamina (C) e diaminoetano (D).

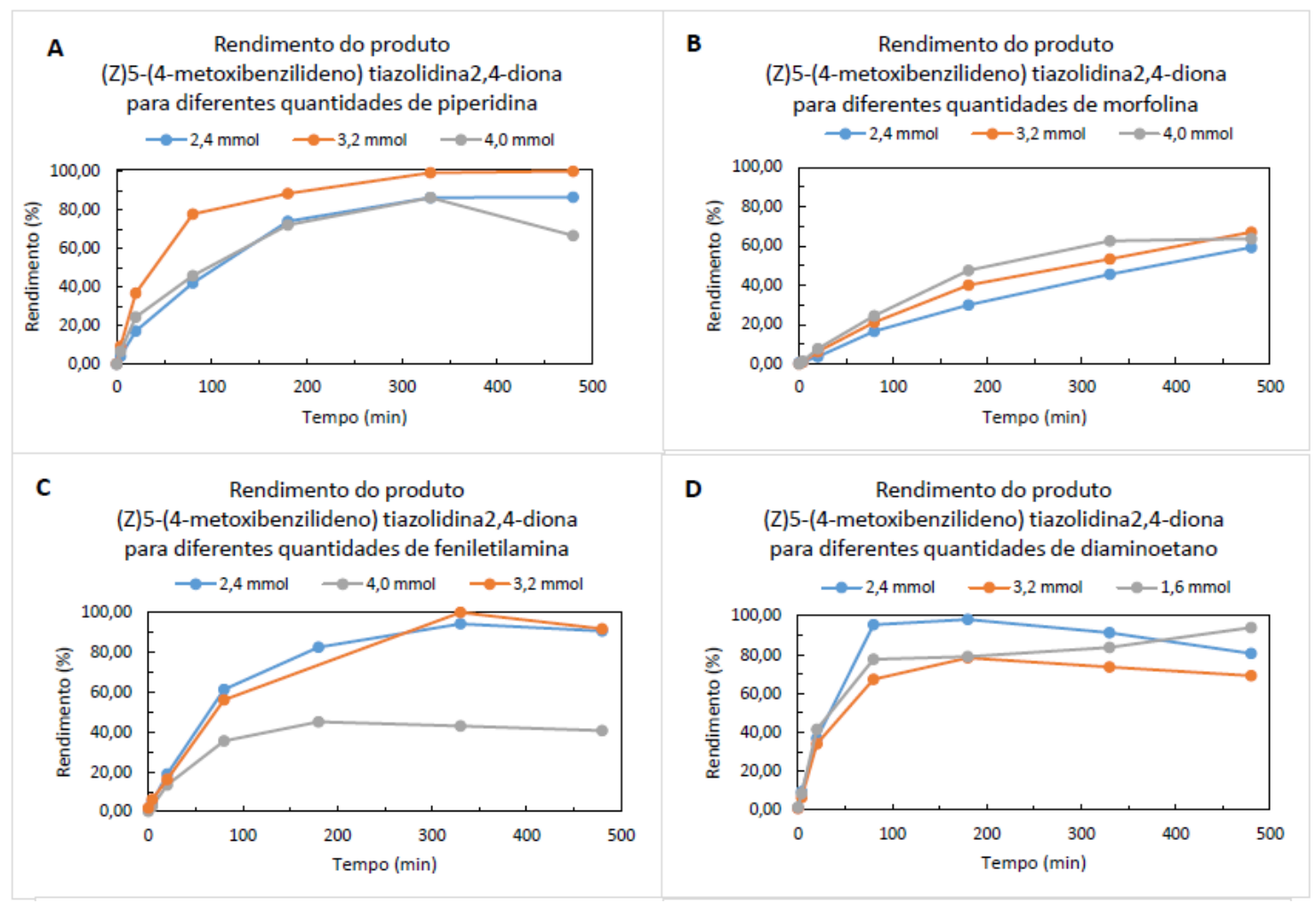

Analisando os resultados preliminares obtidos para a piperidina (Fig. 3A), notase que o maior rendimento e a maior velocidade inicial da reação foi obtida para 3,2 mmol de piperidina. Os resultados para 2,4 e 4,0 mol são bastante semelhantes, com a diferença de que no excesso de catalisador, ocorre uma queda brusca na quantidade produto ao final da reação.

Segundo Baranov (1965) a condensação de Knoevenagel da TZD com o benzaldeído não apresenta reações secundárias. Como o mecanismo de reação para com o p-anisaldeído é similar, pode-se assumir também que não há reações secundárias e formação de subprodutos. Deste modo, a queda no rendimento do produto ao fim da reação provavelmente se deve à degradação deste devido ao excesso de catalisador. $\mathrm{O}$ produto (Z) 5-(4-metoxibenzilideno)tiazolidina-2,4-diona apresenta um grupo metileno ativado que ainda pode seguir outras rotas reacionais na presença de catalisador. Provavelmente este fato só se observa quando há excesso de catalisador, pois, como a reação de formação do derivado tem cinética mais favorável, somente quando as concentrações de produto e de catalisador forem altas, a reação de degradação terá efeitos perceptíveis.

Quanto à velocidade inicial para 4,0 mmol observa-se velocidade inicial maior do que para 2,4 mmol, mas ainda sim inferior à obtida para 3,2 mmol. Apesar destes resultados serem preliminares, é possível afirmar que a quantidade ótima de piperidina é 
inferior a 4,0 e superior a 2,4 mmol e, provavelmente, se encontra próxima de 3,2 mmol.

Já para o catalisador morfolina (Fig. 3B), a quantidade de 4,0 mmol apresentou maior velocidade inicial, mas comparando os pontos finais para as curvas para 2,4 e 4,0 mmol com a curva para 3,2 mmol, observa-se que para 2,4 e 4,0 mmol houve redução na velocidade da reação, provavelmente também devido à degradação do produto após 400 min. Desse modo, a quantidade ótima de catalisador também deve estar em torno de $3,2 \mathrm{mmol}$.

Para a feniletilamina (Fig. 3C), observa-se que o rendimento do produto varia consideravelmente com a quantidade de catalisador no meio, sendo evidente o fato que o produto é degradado na presença de excesso de catalisador. Neste caso, a reação apresentou elevada velocidade inicial para os três casos, contudo o rendimento final de produto variou de $40,7 \%(4,0 \mathrm{mmol})$ a $91,7 \%$ (3,2 $\mathrm{mmol})$, indicando que o rendimento máximo de produto ocorre em torno dos 330 min de reação e que a quantidade ótima de catalisador está entre 2,4 e 3,2 mmol. Mais estudos serão feitos em pontos intermediários deste intervalo para buscar identificar a quantidade ótima de catalisador.

O diaminoetano (Fig. 3D) também apresentou elevada velocidade inicial, bem como elevado rendimento de produto atingindo $98,7 \%$ em $80 \mathrm{~min}$. Tanto para 2,4 mmol quanto para 3,2 mmol houve degradação de produto após $200 \mathrm{~min}$. Para este catalisador a quantidade ótima provavelmente é inferior a 2,4 mmol e, além disso, o tempo de reação utilizado deve ser inferior a 480 min para evitar degradação do produto, comprovada pela mudança de cor e liberação de gás $\mathrm{H}_{2} \mathrm{~S}$ observada após 200 min de reação. Para testar esta hipótese, foi realizado um ensaio com 1,6 mmol e, conforme esperado, não se observou queda no rendimento do produto, apesar de o rendimento máximo observado ter sido inferior. Será testada também a concentração de 2,0 mmol.

$\mathrm{Na}$ Tabela 1 são comparadas as velocidades iniciais médias para 4 catalisadores entre 0 a 4 min.

Tabela 1 - Velocidade inicial da reação, $V i$, para os catalisadores piperidina, morfolina, feniletilamina e diaminoetano.

\begin{tabular}{cccc}
\cline { 2 - 4 } & \multicolumn{3}{c}{$\begin{array}{c}\mathbf{V i} \\
(\mathbf{m m o l} / \mathbf{m i n})\end{array}$} \\
\cline { 2 - 4 } & \multicolumn{3}{c}{$\begin{array}{c}\text { Quantidade de catalisador } \\
(\mathbf{m m o l})\end{array}$} \\
\hline Catalisador & $\mathbf{2 , 4}$ & $\mathbf{3 , 2}$ & $\mathbf{4 , 0}$ \\
\hline Piperidina & $3,59 \mathrm{E}-02$ & $8,15 \mathrm{E}-02$ & $5,92 \mathrm{E}-02$ \\
\hline Morfolina & $3,06 \mathrm{E}-03$ & $7,76 \mathrm{E}-03$ & $1,24 \mathrm{E}-02$ \\
\hline Feniltilamina & $3,47 \mathrm{E}-02$ & $3,82 \mathrm{E}-02$ & $2,34 \mathrm{E}-02$ \\
\hline Diaminoetano & $7,47 \mathrm{E}-02$ & $5,07 \mathrm{E}-02$ & ----- \\
\hline
\end{tabular}


Analisando a Tabela 1, conclui-se que dentre os catalisadores analisados, 3,2 mmol de piperidina apresenta a maior velocidade inicial de reação apesar de o diamnioetano apresentar um valor bem próximo. Entretanto, vale ressaltar que os resultados para diaminoetano são mais interessantes por manter a alta velocidade inicial por mais tempo, atingindo o rendimento máximo em um tempo inferior ao da piperidina.

\section{REFERÊNCIAS}

BARANOV, S. N; KOMARTISA, L. D. Study of the Reactivity of the Methylene Hydrogen Atoms of Some Azolidines. III*. Kinectics od the Reaction of Azolidones-4 with Benzaldehyde. Chemistry of Heterocyclic Compounds, v. 1, pp 46-48, 1965.

CUNHA, S.; SANTANA, L. L. B. Condensação de knoevenagel de aldeídos aromáticos com o ácido de meldrum em água: uma aula experimental de química orgânica verde. Quim. Nova, v.35, n.3, p.642-647, 2012.

MISHRA, G.; SACHAN, N.; CHAWLA, P. Synthesis and Evaluation of Thiazolidinedione-Coumarin Adducts as Antidiabetic, Anti-Inflammatory and Antioxidant Agents. Letter in Organic Chemistry, v.12, p.429-445, 2015.

MOHANTY, S.; REDDY, S.G.; RAMADEVI, B.; KARMAKAR, A.C. An assembly of structurally diverse small and simple 5-aminomethylene derivatives of 2,4thiazolidinedione and studies of their biological activity. Med. Chem. Res., v.24, p.4037-4049, 2015

XU, L.; PENG, J.; SRINIVASAKANNANC, C.; CHENA, G.; SHEN, A.Q. Synthesis of copper nanocolloids using a continuous flow based microreactor. Applied Surface Science, v.355, p.1-6, 2015.

WATTS, P.; WILES, C. Micro reactors, flow reactors and continuous flow synthesis. Journal of Chemical Research, v.4, p.181-193, 2012. 